This is a post-peer-review, pre-copy-edit author version of an article which has been published in its definitive form in Omega and has been posted for personal use, not for redistribution. The article was published in:

Omega - International Journal of Management Science, (2001), 29(4): 343-359

\title{
TQM implementation: an empirical examination and proposed generic
}

\section{model}

\author{
Abby Ghobadian, and David Gallear \\ Business School, Middlesex University, The Burroughs, London NW4 4BT, UK
}

\begin{abstract}
Total quality management (TQM) is considered by many as an important quality and business performance improvement tool. The popularity of the concept has led to an explosion of TQM related literature. A careful review of the literature suggests that most publications recount the experiences or perceptions of the authors or deal with single case organisations. Furthermore, there is a dearth of empirical research and literature dealing with TQM's implementation process. This paper reports the findings of a research project that empirically examined the process of TQM implementation in a sample of organisations widely regarded as leading exponents of TQM. The paper presents a non-prescriptive model of the TQM implementation process derived from the findings and proposes an "outcome driven" approach as an alternative to the more commonplace TQM implementation strategies.
\end{abstract}

Keywords- total quality management, implementation process, organizational change, nonprescriptive model. 


\section{INTRODUCTION}

Total Quality Management (TQM) is one of the most popular and durable modern management concepts. This position is rooted in its development which has passed through a number of phases since the 1920s: quality control (QC); quality assurance (QA) and total quality control (TQC). Each subsequent phase has extended the scope of the concept. Amongst the most significant factors that have contributed to the persistence and strength of the TQM model are: (i) recognition and demonstration of the importance of "quality" as a source of superior competitiveness $[9,49,11,13]$; (ii) the success of Japanese firms in taking and retaining market share from their Western counterparts $[15,45]$; (iii) influence of the teaching and writings of scholars such as Deming, Juran, Crosby and Feigenbaum, collectively referred to as the 'quality gurus' [17]; and (iv) introduction of internationally recognised quality awards such as the Deming Prize, and the Malcolm Baldrige, European and Australian Quality Awards [18].

As with most management interventions TQM has not been without its critics. A number of publications have suggested that TQM has failed to deliver expected results $[42,54,8]$. Such views are countered by the argument that to dismiss TQM on the basis of "loose" negatively-oriented evidence is irrational. Ever since the late 1980s when the positive correlation between introduction of TQM and enhanced competitiveness began to be understood, evidence has suggested that the majority of organisations that have introduced TQM believe that it has helped them to increase their market share and improve their competitiveness [26, 45, 37]. Furthermore, studies that have been devoted to examining the relationship between TQM and performance using factual rather than perceptual data [for example 12, 41,6], by and large have concluded that there is a cause and effect relationship between TQM practices and healthy or improved corporate performance.

\section{THE INFLUENCE OF THE IMPLEMENTATION PROCESS}

The importance of TQM as a means of improving performance has captured the attention of many researchers and writers. An examination of relevant databases bears witness to the large increase 
since the early 1980s in the volume of TQM related publications and the range/variety of types of publications where TQM related contributions appear ${ }^{1}$. Furthermore, these publications range from those dedicated to the subject to those concerned with marketing, economics, general management, personnel and human resource management, industrial engineering and strategic management.

\subsection{Importance of implementation process}

It is broadly agreed that central to the long term success of TQM within an organisation is the implementation process $[47,43,1,38,52]$. Motwani [38] proposed that TQM will nearly always work when the proper methods to execute it are employed. Shin et al [52] argued that when TQM has failed, it is not because there was a basic flaw in the principles of TQM, but because an effective system was not created to execute TQM principles properly. Similarly, Reger et al [47] noted that as instances of TQM failures begin to surface ${ }^{2}$, the weaknesses are usually, though not entirely, attributed to implementation problems. Newall and Dale [40] studied the problems encountered in implementing TQM and other quality improvement initiatives in eight UK based companies. They concluded that one of the key reasons for future difficulties was poor planning in the introduction stages. Moreover, they pointed out that lack of detailed planning prior to the introduction of quality improvement initiatives had a "knock-on" effect throughout its development and subsequent advancement. These views indicate that the introduction of a TQM approach is not without difficulty. It may be argued that the sheer scale of the change inherent in moving away from the conventional management model towards TQM contributes heavily to this difficulty. Grant et al [21] suggested that the implementation of TQM provided a challenge similar to those involved in the management of other revolutionary transitions - once underway how does the organisation "keep the lid on it?" [15].

\footnotetext{
${ }^{1}$ For example, the ABI Inform CD-ROM Database, which provides citations of articles in a large and diverse number of journals dealing with management-related issues, revealed that between January 1986 and December 1991 a total of 407 articles were referenced. Between January 1992 and December 1995 the number of articles referenced was 2281 - a significant increase in volume.

${ }^{2}$ Reger et al [47] did however note that studies reporting the failures have provided scant theoretical justification for their results.
} 
Implementation process is important for a number of reasons. Central to these is the requirement that for TQM to take root successfully in the longterm, it must have a positive influence not only on employees' behaviour, but also on their attitudes and values. Ahire and Rana [1] proposed that as with any new concept, the extent to which TQM will be successful in any organisation is determined by its initial impact and its perceived worth as a new way of operating. According to Ahire and Rana [1], the literature dealing with participative decision making and organisational dynamics points to the fact that any new technical or management approach is either accepted sincerely or rejected based on the first few experiences with it. This led them to postulate that the first impression of the initial phase of TQM implementation contributes significantly to the long-term confidence and support of all participants in a TQM approach.

\subsection{Implementation process: a brief review of the literature}

Despite TQM's perceived importance, examination of the published material reveals that little attention has been devoted to examining the TQM implementation process. This is in contrast to identification and examination of its prevalent components [12, 33, 44, 3, 59]. Moreover, it appears that examination and discussion of TQM implementation is dominated by single case evidence [60, $32,46,35]$. When these case study contributions are examined it becomes clear that in many the implementation "process" is only cursorily examined. Rather, attention is paid only to the introduction process of specific parts or elements of TQM approach. More substantial case studies that do deal with the process of implementation can be found in Whittle and McNiven [57], Seel [51], Wellburn [56] and Wilshaw and Dale [61] for example. Review of these contributions is beyond the scope of this paper. Nevertheless, it is clear upon examination that most concern organisations that at the time the study took place were relatively new to TQM, and thus provide a fairly limited picture. An extensive review of the literature revealed only three empirical multiple-organisation studies primarily dedicated to the examination of TQM implementation process [40, 33, 22, 23]. Mann and Kehoe [33] examined the process of TQM implementation in 21 UK based organisations with at least two years experience of TQM and concluded that the implementation processes used were largely diverse and there appeared to be no one dominant approach. The data led them to conclude that there appeared to be no optimum approach to implementation. Harte and Dale $[22,23]$ examined the 
process of TQM implementation in eight professional service organisations. They too found that a variety of means for launching TQM were used, though most followed the same basic process: diagnosis; goal determination; and implementation. Newall and Dale [40] concluded from their study of eight UK organisations (seven were manufacturers) that despite the different interpretations and descriptions of the development of the quality improvement process, companies do pass through a number of discrete phases during the introduction of TQM. They identified six phases: awareness; education and training; consolidation; planning, problem identification and problem solving; implementation of quality improvement plans; and assessment.

A number of studies have examined the process of implementation as a part of a broader study of TQM $[31,29,44]$. The common conclusion of these studies was that implementation was firm specific. Based on their own review of the TQM literature, Shin et al [52] concluded that implementation should be unique to each company. They argued that success of TQM is a function of many variables (both controllable and uncontrollable), and many of them are unique to the company situation. Therefore, they concluded, each company should tailor its approach to exploit its unique strengths and focus on its particular weaknesses. Furthermore, a number of researchers and authors have noted that for all the attention TQM has received, there appears to be an apparent neglect of the design issue $[19,55,34]$. That is to say, that there appears to have been little research attention devoted to the development of empirically grounded, practical diagnostic tools, that can provide guidance to the TQM designers in their endeavours to appropriately customise their organisation's TQM implementation efforts. It may be argued that existing knowledge about the process of TQM implementation remains highly fragmented.

\subsection{Emergent research questions}

Brief review of the existing literature presented above suggests that implementation process influences the short and long term success of TQM, and that TQM implementation process is an under researched area. Findings and conclusions drawn about the "full" process of implementation appear to be rarely presented. From a practical viewpoint, it may be argued that the process of implementing TQM in organisations has been and continues to be directed largely by anecdotal 
evidence or prescription rather than hard empirical data. There is a clear need for substantive research to extend the current knowledge and understanding of the process of TQM implementation and, to support the future development of TQM.

The widely held view expressed in the literature, that TQM must be customised to an organisation's specific needs, led the authors to put forward two pertinent research questions relating to the process of TQM implementation. It was the purpose of this investigation to address these research questions.

\section{Question one}

'Is there commonality in the implementation processes of successful TQM organisations ?'.

\section{Question two}

'If there is commonality in these implementation processes, does the commonality lie at a level deeper than the activity level ${ }^{3}$ ?'.

A further stated objective of this research was to develop a non-prescriptive model of TQM implementation. The rationale for a non-prescriptive model was two pronged. Firstly, to provide a useful framework within which practitioners and researchers can place other evidence in order to enhance their understanding of the complexities and salient features of implementation. Secondly, this form of research output takes heed of the need to recognise that different organisations have different contingencies in terms of their internal and external environments and therefore that the detail of implementation - the activities and tactics - may differ substantially.

It was not the purpose of this research to revisit questions relating to the "content" or "principles" of TQM. Many other studies have tackled this area. Some of these studies were referred to in section 2.2. This paper focuses solely on the implementation process - an issue only partially discussed in the current literature but critical to TQM success. The timing of the paper is of particular importance. Despite the considerable volume of TQM related publication the literature remains

\footnotetext{
${ }^{3}$ Activity level refers to tangible operational methods, tools or techniques. That is, to actual practices or actions, versus objectives or intentions. Activities correspond to what actually happens on the ground - the tangible initiatives that are put into place in support of a broader objective or an intention.
} 
fragmented. As Hackman and Wageman [24] proposed, three worrisome trends are evident: (a) large amounts of rhetoric are winning over substance, (b) an astonishing number of other interventions, some related to TQM and some not, are increasingly being presented under the TQM banner and (c) too much of the literature consists of anecdotal case reports that they suggested may be of more use politically in promoting TQM than in building knowledge about TQM processes. This paper aims to add to the scant knowledge about TQM implementation process by systematically examining wide ranging first-hand TQM implementation, and synthesizing the findings into a model. The authors contend that this contribution addresses the concerns expressed by Hackman and Wageman [24] among others, and fills an important gap in the existing knowledge. The next section describes the empirical research undertaken to answer the two emergent research questions put forward.

\section{RESEARCH METHOD}

The primary data used in the investigation were the broad implementation plans of a sample of organisations. These data were collected via a structured postal questionnaire as part of a much broader modified Delphi study of TQM. Figure 1 illustrates the process used for derivation of the questions.

\section{$<<$ FIGURE 1 $1>$}

A combination of extensive literature review and focus group was used to identify the key issues to be addressed by the questions. Whilst broad and wide-ranging, the literature review paid particular attention to evidence describing the process of TQM implementation and the reasons for both success and failure of TQM or its implementation process. Focus group discussion was held to identify any other pertinent issues relating to TQM implementation that had not been highlighted by the literature review. The focus group members were drawn from colleagues with considerable practical and academic experience of total quality organisations. The findings generated from these two sources were juxtaposed to arrive at a draft questionnaire. A committee of six other known and experienced TQM practitioners from industry and commerce was then used to screen and verify the research instrument prior to its distribution. Of crucial importance to this investigation, the questionnaire 
asked organisations to supply documentary evidence describing their TQM scheme and the implementation plans. The majority of the non-prescriptive model of TQM implementation process presented in section 5 was developed based on analysis of the documentary evidence supplied by the organisations. The domain of the primary data was confined to organisations recognised as leading exponents of TQM. The rationale for this restriction was straightforward. Supported by examination of methodological shortcomings of previous TQM research investigations it was concluded that a great deal more could be learnt from organisations that had achieved a high level of TQM success than from those organisations that had either failed or made little progress. Thus, invitation to participate in the investigation was based on fulfilment of at least one of the following criteria considered to indicate a successful total quality organisation:

- was a past winner, finalist or recipient of certificate of merit from an internationally recognised quality award scheme (European Quality Award, Malcolm Baldrige National Quality Award (USA), Canadian Awards for Business Excellence (Total Quality Category) or Australian Quality Award)

- had been awarded a peer acknowledged quality rating by major customers or vendors

- had received recognition through prestigious professional or academic journals as a total quality organisation.

Simply being a member of a recognised quality institution or foundation was not deemed to guarantee the degree of best practice required for this investigation. Further, the literature indicated that the successful diffusion of TQM practice to 'not-for-profit' organisations was in its infancy and underdeveloped, and therefore the investigation was restricted to the analysis of 'for-profit' organisations. The target sample was constructed and comprised forty-seven benchmark organisations. The single point of contact (respondent) at each organisation was the Quality Director / Corporate Quality Officer or equivalent post. Data was subsequently collected from thirty-five of the benchmark organisations. Thirty-one of these responses provided the detailed documentary evidence of their organisation's TQM implementation plans required by the analysis. Four of the responses were discarded because they did not describe the organisations' implementation plans in sufficient depth. Of these thirty-one organisations, sixteen operated in the manufacturing sector, six operated in the service sector and nine organisations considered themselves to have a dual manufacturing and service business orientation. In terms of size, twenty-one of the organisations were classified as large 
organisations and ten as small to medium-sized enterprises ${ }^{4}$. The organisations' experience of TQM, that is since the commencement of their TQM implementation processes, ranged from three to thirteen years, with an average for the sample of 6.75 years.

\subsection{Data analysis procedure}

A cursory initial examination of the documents supplied by the organisations and detailing their implementation plans indicated significant differences in approach. This suggested that implementation at "activity level" was organisation specific in the sample of benchmark TQM organisations studied by the authors. In effect this finding substantiated the view reported in the literature. Moreover, in relation to the defined research questions, this finding confirmed that if indeed there is commonality in the implementation processes of successful TQM organisations, it must reside at a level other than the "activity level". The reasons for this position are discussed in the following sections.

Consultation of appropriate literature suggests that ultimately implementation is concerned with tactics. This in turn suggests that implementation requires an "operational plan". The purpose of the "operational plan" is to identify a series of activities/actions necessary to the attainment of the desired outcome [25]. Grant [20] defined tactics as schemes for specific actions. Similarly, Rue and Holland [50] suggested that tactical plans were short range plans oriented towards day-to-day business operations. The "operational plan" describes the tactics in the context of that organisation. It was immediately clear that the implementation plans provided by the participants were the "operational plans" of their TQM implementation process. The plans were almost entirely described in terms of "activities" or "initiatives".

Contemporary wisdom suggests that actions taken by or within an organisation, that are uncoupled from goals or objectives, are unlikely to make a value-adding contribution for the medium to long term. Furthermore, that for the activities of a change process to be "cumulatively" value-adding and

\footnotetext{
${ }^{4}$ In this study the authors adopted the size classification used by Eurostat (EC-Directorate General): micro organisations (0-9 employees), small to medium-sized organisations (10-499 employees) and large organisations (+500 employees).
} 
re-enforcing, shifts in the focus of "activity" may be needed as the change process progresses. The authors contend that these arguments suggest that analysing the activities/initiatives identified in operational plans without examining their underlying objectives or the focus of the activity represents a partial analysis. Therefore, the logical progression in the analysis of the implementation plans was to: (a) investigate how and where the implementation plans had an impact on the operation of the organisation, (b) examine the contribution of the implementation initiatives to desired outcomes of implementation process, and (c) examine the sequencing of the implementation activity in perspectives of points (a) and (b) above. In short, the immediate objective of the analysis became examination of (a) "focus" of the implementation activity, (b) "rationale" for the implementation activity, and (c) "phasing" of the implementation activity. Each was achieved through a combination of qualitative and quantitative analysis.

\section{"Focus" of the activity}

Logically, each implementation activity or initiative has a "focus" and addresses a specific element of the TQM concept. The model proposed by Ghobadian [14] was used to allocate the TQM activities and initiatives to the relevant element of the TQM concept. The model used is based on inductive research of TQM in other successful companies. It is an integrative model for TQM where only the key elements are predefined. The model is depicted in figure 2.

\section{$<$ FIGURE $2>>$}

The main elements can be subdivided into a number of TQM sub-elements, however these are purposely not pre-specified. The rationale for this is that the responsibility for identification of the sub-elements (improvement projects, methods, processes and working practices) underpinning the TQM approach rests with the organisation because, to a large extent, these are contingency dependent. Management process (i.e. management practices and attitudes) is the key element in the TQM approach and permeates the other four main focus elements. These are: (a) the direction of the organisation focus - this should be external, aiming to meet the needs of the customer; (b) process focus around the outcome requirements rather than the tasks; (c) people focus; and (d) communications and measurements. 
Because this model is not prescriptive and not sequential, it was considered to be an appropriate and systematic framework to form the basis for the analysis. Each different type of implementation activity/initiative was allocated to the appropriate principal element of TQM. For example, "competitive benchmarking" was allocated to market focus, "process improvement teams" was allocated to process focus and "training" was allocated to people focus. Appendix 1 cites the different implementation initiatives and the TQM main element to which they were assigned.

\section{"Rationale" for the activity}

Logically, each activity or initiative has a "rationale", that is they are there to facilitate the attainment of a goal or objective that forms a part of the process of change. "Rationale" for the implementation activity was examined and each activity or initiative was allocated to the relevant desired outcomes. As was mentioned previously the study reported in this paper forms a part of a broader Delphi Study of TQM with the aim of developing a theoretical foundation for TQM and these desired outcomes were identified as a part of this broader study.

"Phasing" of the implementation activity is discussed in section 4.3.

\section{FINDINGS}

In total, the thirty-one implementation plans provided by the thirty-one organisations cited 531 implementation initiatives. These represented a wide range of different types of initiatives. The number of initiatives contained in individual organisation's plans ranged from six up to thirty-five. The average number of initiatives per implementation plan was seventeen. Interestingly, there was no correlation between size of organisations and the number of initiatives in organisations' implementation plans. The most common implementation initiatives were:

- training,

- TQM education course,

- teamwork (problem solving/improvement),

- create quality council/steering group, 
- quality assurance processes,

- $\operatorname{mission/vision~development,~and~}$

- teamwork (work management).

Training initiatives featured heavily. The total number of references to training in the sample's plans was fifty four. Of these, twenty seven were specified in terms of who the training was directed at. The other twenty seven were specified in terms of specific types of training. Organisations made a clear distinction between training and education. TQM education course initiatives were all made with reference to whom in the organisation the TQM education was directed at, with senior management constituting the largest proportion. Teamwork, in its various forms, also featured heavily. Thirty-nine references to teamwork were made. The remaining three initiatives in the above list, create quality council/steering group, quality assurance processes and mission/vision development were cited sixteen, fourteen and thirteen times respectively. All other activities/initiatives were mentioned less than ten times each.

\subsection{Findings - "Focus" of the activity}

The 531 implementation initiatives were allocated to the five salient elements of TQM using the model presented in figure 2. The results are illustrated in figure 3. The largest number of activities and initiatives fell under management process and people focus, accounting for 161 and 167 implementation initiatives respectively. Indeed, each of the seven most common initiatives referred to above were classified under either management process or people focus. Communication and measurement accounted for 93 initiatives. Market focus accounted for 61 initiatives, and process focus accounted for the smallest number of initiatives, 47 in total.

$<<$ FIGURE 3>>

These findings indicated that the main focus of the implementation plans was on the introduction of activities and initiatives that would beneficially affect the organisations' management process and its people orientation. The analysis also suggested that although, conceptually, 'customer orientation' is 
perhaps the central tenet of an established TQM approach, the planned implementation of TQM was primarily concerned with gearing up the "internal competency" of the organisation to effect change and to cope with change, in readiness for a shift in focus to customer orientation later in the TQM development. Similarly, there appeared to be some disparity between the perceived importance of process focus as a main element of an established TQM approach, and the scale of process focus oriented action taken during the planned TQM implementation processes studied. However, when consideration is given to what is involved in changing from a functional/task orientation to a process orientation, the data makes more sense. Process orientation represents an integrated approach to organizing the work of the organisation, and therefore its achievement represents major operational and structural change within the organisation. The process orientation defines new management and employee roles and responsibilities, such as process owners, and requires the development and subsequent awareness and use of communication channels. People at all levels must cooperate in gaining and sharing knowledge about business processes. It is therefore important that the organisational infrastructure is made ready to adapt to the changes that process orientation will necessitate, for example, that the output from process improvement team activity can be incorporated into the organisation's operations. Boaden and Dale [4] have observed that not all attempts at process analysis and improvement are successful, and they suggested that in many cases management appears not to have fully understood the concepts or has not been able to apply them organisation wide. Clearly, as these arguments illustrate, change to process orientation is a considerable undertaking. The data supports the assertion that a key component of achieving an organisational transformation is to allow employees to get comfortable with change.

\subsection{Findings - "Rationale" for the activity}

Examination and consideration of the individual merits of the implementation initiatives indicated that some had a very clear cut objective. On the other hand some initiatives had multiple purpose and goals. These predominately had an identifiable principal objective, but also fulfilled a number of other roles that contributed positively to the process of change. The research identified seventeen "desirable outcomes" associated with the change relevant to the process of implementing TQM. Following this the implementation initiatives capable of supporting the attainment of each of the 
desirable outcomes were heuristically identified. In each case, those initiatives that would make a significant contribution were distinguished form those that would make a supporting/token contribution. This distinction was made primarily to augment clarity of the analysis ${ }^{5}$. Figure 4 shows the extent to which the seventeen desirable outcomes were supported in the sample's TQM implementation plans. The magnitude of each bar in the chart represents the number of activities or initiatives in the sample's implementation plans that were allocated to that desired outcome.

\section{$<<$ FIGURE 4>>}

This analysis suggests that the planned implementation of TQM is heavily concerned with the development of internal improvement capability. The planned implementation also appears to incorporate many initiatives that address attitudinal aspects. That is, initiatives that help to increase the level of trust amongst the members of the organisation, that help to instil a sense of ownership and shared responsibility, and that help to nurture a willingness to change. These appear to be complemented by initiatives in the domain of providing direction and guidance, that is initiatives that help improve clarity of organisational objectives and that help to move from perceptual to fact-based decision making. Furthermore, directly supporting these latter aspects, are initiatives that not only help to increase the amount of information sharing within the organisation, but more importantly, that help to increase the ease of information sharing. It may be argued that the analysis has demonstrated that though the specific activity requirements of organisations' TQM implementation processes may differ widely, the "activity" nevertheless has common underlying objectives and roles.

\subsection{The "phasing" of the implementation process}

Having examined the constitution of the implementation plans we now turn our attention to examining when, during the implementation process, the "focus" of the activity and the "rationale" for the activity features. That is, to examine the "phasing" of the implementation process. "Phasing"

\footnotetext{
${ }^{5}$ For example, the initiative training to a certain extent would make a contribution to all seventeen of the "desirable outcomes".
} 
refers to the broad characteristics of the sequence and flow of TQM implementation ${ }^{6}$. Theoretically, the options for how to phase the implementation initiatives can span a continuum, with the simultaneous introduction of all new initiatives at one extreme, and the sequential introduction of initiatives one-by-one at the other extreme. The latter appears to be the approach most prescribed in the TQM literature. In view of the analytical complexity of examining and comparing the constitution of thirty-one independently derived implementation plans from viewpoint of "focus" and "rationale" in conjunction with the added dimension of their sequencing, a qualitative correlative approach against a set of pre-identified alternative phasing approaches appeared to provide the most logical examination strategy. Furthermore, this approach could potentially overcome any examination difficulties brought about by variations amongst the plans with regard to: (a) inconsistencies in the manner of phasing representation; and (b) differing number of phases indicated.

Through secondary research seven interpretations of change process phases were identified $[16,7$, 10, 30, 19, 2, 36]. These are presented in table 1. Each interpretation was iteratively compared against each of the sample's implementation plans. Through this deductive research, common features amongst implementation plans were identified. This iterative process suggested that the majority of the thirty-one implementation plans followed a four phase implementation approach: start-up (launch); transition; consolidation; maturity/re-focusing. In the majority of implementation plans these four phases were clearly visible, however each phase was not necessarily mutually exclusive. Rather, the phases exist along an implementation continuum where the weight of evidence strongly indicated the four substantially different foci. A brief definition was developed for each phase as part of this process. These are given below. The associated bullet points describe the characteristics of each of the suggested phases:

\section{$<<$ TABLE 1 $>$}

\footnotetext{
${ }^{6}$ A phase refers to a stage of change or development in an implementation approach, in contrast to a step, which refers to a specific piece of action. Usually a phase will comprise a number of steps.
} 
Phase 1 - Start-up (launch) - Initial phase preceding the development of the main operational features of the plan. This phase helps to shape the fuller development of the implementation by creating the suitable conditions. It is characterized by (and/or):

- awakening

- identification and preparation

- intent

Phase 2 - Transition - Phase in which the implementation intentions are acted on causing a change from the original state or set of circumstances to others. It is characterised by, (and/or):

- variety generation

- increasing the participation

- mobilize

- power shift

Phase 3 - Consolidation - Phase in which any necessary or desired actions are taken or occur to strengthen or initiate the combining of TQM and/or normal business processes into one whole. It is characterised by, (and/or):

- transformation

- spread / institutionalize revitalization

- (operational integration)

- business alignment

- organization for genuine continuous improvement

Phase 4 - Maturity/refocussing - Phase during which the now experienced and competent TQM practitioners monitor and/or adjust strategies or operations in response to (a) outcomes of consolidation, and/or (b) wider changes in business requirements. It is characterised by, (and/or): 
- necessary activities

- new initiatives with new targets and critical examination

Having established the prevalent implementation approach, it was possible to apply this phasing scheme to each implementation plan, to examine how the "focus" of activity and "rationale" for the activity alters as implementation progresses. After applying the phasing scheme to each of the thirtyone implementation plans, the number of times each type of activity or initiative featured in each of the four phases respectively were counted. Having already allocated each type of activity or initiative to the relevant element of the TQM concept, it was then possible to determine the constitution of each of the four phases in terms of the five principal elements. Figure 5 depicts the contribution of the five elements of TQM concept in each of the four phases of implementation. Phases 1 and 2 were found to have a number of salient features distinguishing them clearly from the other phases. Though perhaps to a lesser extent, phase 3 also had distinguishing features.

\section{$<$ FIGURE $5>>$}

Phase 1 (start-up (launch)) specific features:

Figure 5 illustrates that phase 1 of implementation was dominated by initiatives classified under "management process" (57 out of a total of 121 initiatives in phase 1). Three quarters of the quality steering groups were set up in phase 1. The remaining quarter were set up in phase 2. Development of mission/vision of the organisation where previously absent predominantly occurred in phase 1. The initiatives strategic / long-range plan development and strategic goals development were also concentrated mainly (seven from a total of twelve) in phase 1, and again all of the remainder occurred in phase 2. Quality or business process objectives development were equally concentrated in both phase 1 and phase 2. Half of the implementation initiatives that related to TQM leadership appointments occurred in phase 1 , with the majority of the remainder occurring in phase 2. Perhaps not surprisingly, all references to board agreement to develop TQM concept group-wide, and threequarters of the references to gain management support occurred in phase 1. 
There were very few instances of implementation activities classified under "market focus" in phase 1. This was with the exception however of the initiative business environment (current and future) analysis, which featured five times, all in the first phase. The vast majority of TQM research initiatives ("communication and measurement") were conducted in implementation phase 1. Solicitation and awareness initiatives ("communication and measurement") also tended primarily to be initiated in phase 1 .

\section{Phase 2 (transition) specific features:}

Figure 5 shows that in phase 2, the dominating emphasis in the sample's implementation plans shifted from "management process" that dominated phase 1, to the initiatives classified under "people focus". However, "management process" still commanded a significant proportion of the initiatives in phase 2.

Training was the first, and very significant distinguishing feature of phase 2 of implementation, cited a total of forty-eight times. In phase 1 of implementation, training was only cited twice, and in phase 3 it was only mentioned three times. The initiative TQM education course was also most predominant (approximately two thirds of instances) in phase 2. The other third of TQM education course initiatives had been initiated in the previous phase, phase 1. Further examination indicated that whereas in phase 1 the focus of the education courses was concentrated on senior management, in phase 2 the focus concentrated on organisation-wide education All of the references to TQM education course were made either in phase 1 or 2 . It was in phase 2 that the vast majority of activities concerning the assessment of the "employee perception" position of the organisation were initiated, for example employee satisfaction surveys. Just over half of the recognition and reward implementation initiatives were brought into the implementation process in phase 2 . The remainder were introduced in phase 3.

The initiation of teamworking activity was the second distinguishing feature in phase 2. All of the instances of introducing teamwork for problem solving/improvement and all of the more specialised 
types of teamworking classified under "people focus" were initiated in phase 2. The introduction of teamwork for work management was also concentrated predominantly in phase 2 .

The third and fourth distinguishing features in phase 2 both related to the "management process" category of implementation activity. The third major feature was the initiation of improvement projects. All references to flagship improvement projects and all references to quality improvement projects in the sample's implementation plans occurred in phase 2 . The fourth was that two thirds of the implementation initiatives directly relating to restructuring were initiated in phase 2 . These were: flatten organisation structure and restructuring the spans of control. The fifth distinguishing feature in phase 2, which relates to the "communication and measurement" category, was the vast majority of references to the implementation initiative develop communication channels.

A number of the types of implementation initiatives featured in all four phases but were most predominant in phase 2. These were:

- initiation of benchmarking

- $\quad$ quality assurance processes

- employee involvement.

Activity that centred on empowering employees beyond their traditional boundaries was equally distributed between phases 2 and 3 .

"Process focus" was the implementation activity category that was found to be least explicitly represented in the sample's implementation plans (section 4.1). As figure 5 illustrates, the vast majority of "process focus" activities were initiated or occurred in phase 2. Process improvement teams were brought into the implementation process primarily as part of phase 2. All instances of the introduction of the internal customer/supplier concept occurred in phase 2 , as did the instances of taking ownership of processes. Problem solving methods and quality function deployment (QFD) were also introduced primarily in phase 2. "Market focus" was the other activity category that was found to be un-substantially explicitly represented in the sample's implementation plans. However, as figure 5 clearly shows, despite the overall low counts for the majority of the "market focus" 
initiatives, a substantial amount of implementation activity relating to suppliers and to customers was initiated in phase 2. All supplier development initiatives were initiated in phase 2. In addition, half of the supplier partnership arrangements were initiated in phase 2 . The initiation of diagnostic quality issues survey of customers was most predominant in phase 1, with the remainder of references to this initiative occurring in phase 2. However, phase 2 featured two thirds of the references to the initiation of customer satisfaction surveys.

\section{Phase 3 (consolidation) specific features:}

As stated above, though perhaps to a lesser extent than phases 1 or 2 , phase 3 - consolidation also had distinguishing features. One of the specific features was the setting up of specific forms of communication mechanisms, such as team briefings, regular communications/quality meetings, quarterly reviews and periodic reviews. The introduction of formal self-assessment was concentrated in phase 3, as was introduction of suggestion schemes.

\section{Phase 4 (maturity/refocussing):}

As figure 5 illustrates phase 4 (maturity and re-focusing) contained very few initiatives. Logically, less activity would be expected in this phase. Nevertheless, the finding prompted the question as to whether or not there actually was a distinguishable fourth phase. Phase 4 is about re-focusing, that is to say, adjusting strategies or operations in response to the cumulative experience gained during the earlier three phases. Therefore, it is unlikely that much of phase 4 activity would be defined as part of an organisations' original TQM implementation plan. Furthermore, there were initiatives in phase 4, for example complaint management and customised quality leadership process which based on the previous discussion would have been expected to be in one of the first two phases. Although cited with low frequency in phase 4, their presence here suggested that their identification as a part of implementation was based on knowledge accumulated during implementation, rather than preimplementation knowledge. Hence, they were an outcome of "re-focusing". These arguments suggested that phase 4 is a distinguishable phase in its own right.

\section{Salient features of implementation phasing:}


Cross-referencing the prevalent implementation initiatives in phase 1 against their associated "desirable outcome(s)" that were identified (section 4.2) suggested that during the early period of TQM implementation signified by phase 1 the focus was on helping increase (instil) sense of urgency; taking steps to help to improve the clarity of organisational objectives; putting in place the "management process" related mechanisms that help keep control over the change process; and establishing the knowledge requirements for helping the development of internal capability.

Cross-referencing the prevalent implementation initiatives in phase 2 against their associated "desirable outcome(s)" (section 4.2) suggested that in the second phase of implementation, the focus was on helping to increase the ease of information sharing, helping to instil a sense of ownership and shared responsibility, helping to move from an individual to a team orientation, helping to increase the degree of delegation and empowerment, and as exemplified by the implementation initiatives 'training', 'organisation-wide TQM education' and 'teamwork for problem solving and improvement', helping to develop internal improvement capability.

Figure 5 suggested that in phase 3 the emphasis was no longer on one particular implementation activity category as was the case with the two previous phases. However, what this did infer was that in phase 3 initiatives associated with the activity category "communication and measurement" took a much more active role in the implementation than they had previously. Again, cross referencing the prevalent implementation initiatives in phase 3 against their associated "desirable outcome(s)" (section 4.2) suggested that in phase 3 of implementation the focus is on bolstering the amount of (internal) information sharing, and bolstering the ease of information sharing. The "desirable outcome" helping move from perceptive decision-making to fact based decision making was supported by various implementation initiatives right the way through implementation. However, the cross-referencing suggested that a key focus in phase 3 was on the introduction of new initiatives that consolidate an organisation's ability to achieve this "desirable outcome". In much the same way, a number of phase 3 initiatives appeared to consolidate efforts to improve the clarity of organisational objectives. 
The authors would propose that it is effectively in the fourth phase, maturity and re-focusing, that activities and initiatives supporting market focus and process focus are brought into the TQM implementation process in order for the organisation to attain the "desirable outcomes" of helping to increase the propensity to look to external sources, helping to increase sense of responsibility for the external customer, helping to move from task to process orientation, and helping to move from proven to pioneer mentality.

\section{A NON-PRESCRIPTIVE MODEL OF TQM IMPLEMENTATION PROCESS}

The phasing analysis and findings showed that each of the instances of each type of implementation activity/initiative in the sample's implementation plans were not mutually exclusive to one of the four pre-determined phases of implementation. Moreover, the broad sequence and flow of implementation determinable within the plans studied suggested that the majority followed the four phase approach described above.

A non-prescriptive model is a means of presenting pertinent ideas, pointers and guidelines, and emphasising recommended focuses and constituents in a non-prescriptive manner. That is to say, without prescribing what actual actions should be taken. It allows organisations contemplating the introduction of TQM to identify their specific course of action and priorities. Furthermore, it allows them to identify, research and develop the individual initiatives at a pace that is appropriate to the situation the organisation faces and feasible given the resources available to it. Figure 6 shows the non-prescriptive model of TQM implementation process that was derived from the cumulative findings of the research.

The model suggests that the introduction of TQM consists of three stages: pre-implementation; followed by planned implementation; followed by evolutionary implementation and development. Pre-implementation is first concerned with gaining a thorough knowledge of what can and should be expected from the introduction of TQM, and of the implications of introducing TQM. It is recommended that particular attention is given to: (i) customer expectations and the benefits to be gained, (ii) leadership, responsibilities required and the commitment required, and (iii) 
the probable impact of TQM on the organisation, how to measure progress, and how to communicate the need for change to the organisation. Pre-implementation is then concerned with establishing a team to lead and develop the TQM introduction process, and identifying or developing an appropriate facilitating framework for developing the implementation action plan. Fulfilment of these objectives should then put the organisation in a position to identify the appropriate implementation actions that the organisation requires and to establish the priorities amongst them. Here it is recommended that the organisation make a conscious effort to focus on a small defined set of improvement priorities that align with the organisation's broad business goals and objectives, and that should therefore be realistically deliverable. The final key objective of this pre-implementation stage emphasises the point that responsibility and ownership during this first stage rests with the senior management of the organisation. This final objective is to identify specific responsibilities and areas of ownership during the planned implementation process. The culmination of and fulfilment of these objectives should then result in the production of a structured but flexible and realistic TQM implementation "action" plan customised to the specific needs of the organisation.

The second stage that the introduction of a TQM approach into an organisation goes through is the planned implementation. The model suggests that planned implementation comprises three phases: start-up; progressing into transition; progressing into consolidation. Each of these phases has its own primary areas of focus in order to bring about desirable outcomes that allow the organisation to confidently progress into the next phase.

\section{$<<$ FIGURE $6>>$}

Again, the onus at the start of planned implementation (phase 1 - start-up) is for management of the organisation to get its own house in order, so that it may provide direction and consistent guidance to the rest of the organisation. Recommended key activities in this first phase are: (i) creation of quality steering group and quality leadership appointments, (ii) where not already clearly defined, clarification / development of clear mission/vision, strategy, business process and quality goals and objectives, and (iii) TQM research, management education and solicitation/awareness. Progression into phase 2 - transition, represents the organisation initiating the appropriate activities that expand 
ownership for the change process from primarily management, to the whole of the organisation. The focus is on people and communication. Recommended key initiatives in this second phase are: (i) organisation wide training and education, (ii) problem solving improvement teams, (iii) work management teamworking and management leading by example, (iv) flagship and quality improvement projects, and (v) the development of communication and recognition channels. The third planned phase - consolidation, is primarily concerned with putting in place appropriate mechanisms that will capture and secure: (a) the benefits of increased participation and shared responsibility and (b) the knowledge, skills and capabilities developed, from the previous phase (transition). The focus is on communication and measurement. Recommended key initiatives in this final "planned" stage of implementation are: introduction of team briefing and regular review meetings, introduction of formal organisation-wide self-assessment processes, and (iii) introduction of employee performance and evaluation. As the model suggests, these first three phases of "planned" implementation are concerned with the development of internal improvement capability.

The model suggests that the third stage that the introduction of TQM goes through, or more pertinently goes into, is evolutionary implementation. By this final stage in the introduction, the realistically planned phases of implementation are all but completed. As the right hand side of the model suggests, the organisation is now in a position to exploit the internal improvement capability and use it to effectively re-focus the organisation's efforts on improving the processes that will consistently deliver customer satisfaction. That is to say, re-organisation to customer and market driven process management.

\section{CONCLUSIONS}

The research described here employed a sample of internationally and peer recognised successful TQM organisations as its research domain. The overall frequency of each different type of activity or initiative within the thirty-one implementation plans studied, suggested that in practice there can be a very wide range of implementation tactics. This supports the proposition that there is no single definitive formula for the introduction of TQM. Nevertheless, deeper examination has suggested that 
there are common goals and purposes underlying the activities that make up the implementation process. The authors posed the following two research questions:

Question one: 'Is there commonality in the implementation processes of successful TQM organisations ?'.

Question two: 'If there is commonality in these implementation processes, does the commonality lie at a level deeper than the activity level ?'.

Evidence presented in this paper indicates that the answer to both questions is yes. There is commonality in the implementation processes, and furthermore, the level at which this commonality resides is at the "outcome" level. This level is concerned with the purpose and driving force for the associated tactics.

Findings suggest that organisations that go on to successfully practice the TQM approach use the TQM implementation process as the vehicle for building 'internal capability', before the external influences are then dealt with through customer focus and process focus oriented actions as part of the then established longer term TQM way of working. As Holder and Walker [28] asserted, aligning with the customer and delivering the products and services that customers expect, at a high quality level, are activities which take a lot of effort.

It has been suggested in the broader TQM literature that TQM has a dual make-up; a 'hard-side' and a 'soft-side', where the 'hard-side' focuses on systems, tools and techniques and on establishing standards of performance, and the 'soft-side' concerns attitudes and values reflecting the emphasis given to mobilising all employees around the goal of continuous improvement and enlisting their active commitment by means of participation and responsibility [58, 27, 48, 5]. This investigation has shown that the "planned" implementation process of organisations that go on to successfully practice TQM are weighted heavily in favour of activities that affect the 'soft-side'. However, the 'hard-side' plays two important parts. Firstly at the front-end of the implementation process (start-up) by establishing organisational direction and providing organisational guidance. Secondly, following 
the increase in participation (transition) it helps the organisation to hold the gains and to help to ensure that integration between the new practices and the existing business processes can take place.

To date, literature has suggested that there are two basic strategies for the implementation of TQM: the "activity-driven" approach which is by far the most widely expounded, particularly in the prescriptive literature, and the "results-driven" approach [53, 39]. The "results-driven" approach calls for breakthrough actions. Myers and Ashkenas [39] proposed that substantial results early on are a strong motivator for climbing to even greater performance heights. Proponents of this approach argue that it is not a return to a 'quick-fix' or 'short-term gains at any cost' mentality. In the authors' view, whilst the philosophy of a "results-driven" strategy is appreciated, the investigation reported in this paper calls for the serious consideration of a third alternative approach to the development and subsequent execution of TQM implementation process. The evidence supports the call for an "outcome-driven" approach. In this approach the activities or initiatives of implementation are chosen based on their suitability for systematically effecting the necessary changes in management and employees' behaviour and more importantly in their attitudes. In this way, the implementation process is rolled out in a cumulatively value-adding manner. This in turn can aid the development of long term confidence and support of all participants. Where deemed necessary or appropriate, the approach allows for more specific goals, objectives or targets to be defined for the particular activities or initiatives chosen. Furthermore, the authors would propose that because this approach directly links action to desired outcomes and broader goals, it more directly facilitates the longer term integration of quality and business processes, and helps to guard against the common problem of loss of TQM momentum often associated with the "activity-driven" approach.

\section{REFERENCES}

[1] Ahire, S. L. and Rana, D. S. (1995), "Selection of TQM pilot projects using an MCDM approach", International Journal of Quality \& Reliability Management, Vol. 12 No. 1, pp. 61-81.

[2] Beer, M., Eisenstat, R. A. and Spector, B. (1990), "Why change programs don't produce change", Harvard Business Review, Vol. 68 No. 6, pp. 158-167. 
[3] Benson, T. E. (1992), "IQS: quality is not what you think it is", Industry Week, Vol. 241 No. 19, pp. 22-34.

[4] Boaden, R. J. and Dale, B. G. (1994), "A generic framework for managing quality improvement: theory and practice", Quality Management Journal, Vol. 1 No. 4, pp. 11-29.

[5] Bright, K. and Cooper, C. L. (1993), "Organizational culture and the management of quality: towards a new framework", Journal of Managerial Philosophy, Vol. 8 No. 6, pp. 21-27.

[6] Easton, G. S. and Jarrell, S. M. (1998), "The effects of total quality management on corporate performance: an empirical investigation", Journal of Business, Vol. 71 No. 2, pp. 253-307.

[7] Edwards, J. and Hodgson, A. (1994), "Amersham International Plc: stimulating participation in quality improvement", in Teare, R., Atkinson, C. and Westwood, C. (Eds.), Achieving Quality Performance - Lessons from British Industry, Cassell, London.

[8] Eskildson, L. (1995), "TQM's role in corporate success: analysing the evidence", National Productivity Review, Autumn, pp. 25-38.

[9] Feigenbaum, A. V. (1982), "Quality and business growth today", Quality Progress, November, pp. 22-25.

[10] Foster, M., Smith, S., Whittle, S. and Tranfield, D. (1994), "Regenerating your TQM effort: what to do when it runs out of steam?", The TQM Magazine, Vol. 6 No. 4, pp. 42-47.

[11] Gale, B. T. and Klavans, R. (1985), "Formulating a quality improvement strategy", Journal of Business Strategy, Vol. 5 No. 3, pp. 21-32.

[12] GAO (United States General Accounting Office). (1990), Management Practices: U.S. Companies Improve Performance Through Quality Efforts.

[13] Garvin, D. A. (1987), "Competing on the eight dimensions of quality", Harvard Business Review, November-December, pp. 101-109.

[14] Ghobadian, A. (1993), Integrating Operations Strategy and Quality Improvement: The Way Ahead, Inaugural Professorial Lecture, Middlesex University. 
[15] Ghobadian, A., Gallear, D., Woo, H. and Liu, J. (1998), Total Quality Management: Impact, Introduction and Integration Strategies, CIMA Publishing, London.

[16] Ghobadian, A, Liu, J, Gallear, D and Woo, H. (1996), "Strategies for Integrating Quality and Business Processes", in Proceedings of British Academy of Management Annual Conference (refereed track), 16-18 September 1996, Aston Business School.

[17] Ghobadian, A. and Speller, S. (1994), "Gurus of quality: a framework for comparison", Total Quality Management, Vol. 5 No. 3, pp. 53-69.

[18] Ghobadian, A. and Woo, H. S. (1996), "Characteristics, benefits and shortcomings of four major quality awards", International Journal of Quality \& Reliability Management, Vol. 13 No. 2, pp. 10-45.

[19] Glover, T. (1993), "Achieving the organizational change necessary for successful TQM", International Journal of Quality \& Reliability Management, Vol. 10 No. 6, pp. 47-64.

[20] Grant, R. M. (1997), Contemporary Strategy Analysis: Concepts, Techniques, Applications, Blackwell Business Books, Oxford.

[21] Grant, R. M., Shani, R. and Krishnan, R. (1994), "TQM's challenge to management theory and practice", Sloan Management Review, Vol. 35 No. 2, pp. 25-35.

[22] Harte, H. G. and Dale, B. G. (1995a), "Total quality management in professional services: an examination. Part 1", Managing Service Quality, Vol. 5 No.4, pp. 38-43.

[23] Harte, H. G. and Dale, B. G. (1995b), "Total quality management in professional services: an examination. Part 2", Managing Service Quality, Vol. 5 No. 5, pp. 43-48.

[24] Hackman, J. and Wageman, R. (1995), "Total quality management: empirical, conceptual, and practical issues", Administrative Science Quarterly, Vol. 40 No. 2, pp. 309-334.

[25] Hannagan, T. (1995), Management Concepts \& Practices, Pitman Publishing, London. 
[26] Heller, R. (1994), "Putting the total into total quality", Management Today, August, pp. 5660.

[27] Hill, S. (1991), "How do you make a flexible firm? the total quality model', Work, Employment and Society, Vol. 5 No. 3, pp. 397-415.

[28] Holder, T. and Walker, L. (1993), "TQM implementation", Journal of European Industrial Training, Vol. 17 No. 7, pp. 18-21.

[29] Johnston, C. G. and Daniel, M. J. (1991), "Customer satisfaction through quality", Canadian Business Review, Vol. 18 No. 4, pp. 12-15.

[30] Kanji, G. K. and Asher, M. (1993), Total Quality Management Process: A Systematic Approach, Carfax Publishing, Abingdon.

[31] Lascelles, D. M. and Dale, B. G. (1990), "The use of quality management techniques", Quality Forum, Vol. 16 No. 4, pp. 188-192.

[32] Levine, C. (1993), "How TQM worked for one firm", Journal of Accounting, Vol. 176 No. 3, pp. 73-79.

[33] Mann, R. S. and Kehoe, D. F. (1994), "The implementation of total quality management (paper 2)", Quality World Technical Supplement, March, pp. 57-66.

[34] Mann, R. S. and Kehoe, D. F. (1995), "Factors affecting the implementation and success of TQM", International Journal of Quality \& Reliability Management, Vol. 12 No. 1, pp. 11-23.

[35] McCabe, D. (1996), "The best laid schemes of TQM: strategy, politics and power", New Technology, Work and Employment, Vol. 11 No. 1, pp. 28-38.

[36] Merli, G. (1993), Eurochallenge - The TQM Approach to Capturing Global Markets, IFS Publications, Bedford.

[37] Mohrman, S. A., Tenkasi, R. V., Lawler III, E. E. and Ledford Jr, G. E. (1995), "Total quality management: practice and outcomes in the largest US firms", Employee Relations, Vol. 17 No. 3, pp. 26-41. 
[38] Motwani, J. (1997), "Viewpoint: total quality management or totalled quality management", International Journal of Quality and Reliability Management, Vol. 14 No. 7, pp. 647-650.

[39] Myers, K. and Ashkenas, R. (1993), "Results-driven quality. . .now!", Management Review, Vol. 82 No. 3, pp. 40-44.

[40] Newall, D. and Dale, B. G. (1991), "The introduction and development of a quality improvement process: a study", International Journal of Production Research, Vol. 29 No. 9, pp. 1747-1760.

[41] Oakland, J. S., Zairi, M. and Letza, S. R. (1994), "TQM and Bottom line results", Quality World, September, pp.600-604.

[42] Parker, M. and Slaughter, J. (1993), "Should the labour movement buy TQM?", Journal of Organizational Change Management, Vol. 6 No. 4, pp. 43-56.

[43] Port, O. and Smith, G. (1992), "Quality: small and mid size companies seize the challenge not a moment too soon", Business Week, November, pp. 67-75.

[44] Porter, L. J. and Parker, A. J. (1993), "Total quality management - the critical success factors", Total Quality Management, Vol. 4 No. 1, pp. 13-22.

[45] Powell, T. C. (1995), "Total quality management as competitive advantage: a review and empirical study", Strategic Management Journal, Vol. 16 No. 1, pp. 15-37.

[46] Rau, H. (1995), "15 years and still going ... ", Quality Progress, Vol. 28 No. 7, pp. 57-59.

[47] Reger, R. K., Gustafson, L. T., DeMarie, S. M. and Mullane, J. V. (1994), "Reframing the organisation: why implementing total quality is easier said than done", Academy of Management Review, Vol. 19 No. 3, pp. 565-584.

[48] Rigg, M. (1993), "Organization change and individual behaviour", Industrial Engineering, December, pp. 12-13. 
[49] Ross, J. E. and Shetty, Y. K. (1985), "Making quality a fundamental part of strategy", Long Range Planning, Vol. 18 No. 1, pp. 53-58.

[50] Rue, W. and Holland, P. G. (1989), Strategic Management - Concepts and Experiences, 2nd ed., McGraw-Hill, New York.

[51] Seel, I. C. (1994), "Total Quality at Thomas Cork SML", Managing Service Quality, Vol. 4 No. 5, pp. 21-25.

[52] Shin, D., Kalinowski, J. G. and El-Enein, G. A. (1998), "Critical implementation issues in total quality management", SAM Advanced Management Journal, Vol. 63 No. 1, pp. 10-15.

[53] Steele, J. (1993), "Implementing total quality management for long- and short-term bottomline results", National Productivity Review, Summer, pp. 425-441.

[54] Summers, B. (1993), "Total quality management: what went wrong ?", Corporate Board, Vol. 14 No. 79, pp. 20-25.

[55] Tolchinsky, P. D. and Ranney, J. M. (1994), "Preventing TQM crash landings", Journal for Quality and Participation, Vol. 17 No. 4, pp. 50-57.

[56] Wellburn, J. (1996), "A TQM life cycle case study", The TQM Magazine, Vol. 8 No. 3, pp. $35-45$.

[57] Whittle, A. and McNiven, S. (1993), "A multiple application", Total Quality Management, Vol. 5 No. 2, pp. 27-30.

[58] Wilkinson, A., Marchington, M. and Goodman, J. (1992), "Total quality management and employee involvement", Human Resource Management Journal, Vol. 2 No. 4, pp. 1-20.

[59] Wilkinson, A., Redman, T. and Snape, E. (1995), "New patterns of quality management in the United Kingdom", Quality Management Journal, Winter, pp. 37-51.

[60] Williams, M. (1993), "Cottoning on to the need for change", Total Quality Management, Vol. 5 No. 1, pp. 35-38. 
[61] Wilshaw, G and Dale, B. G. (1996), "Developing a continuous improvement philosophy in a marketing organisation: an examination of key events", The Service Industries Journal, Vol. 16 No. 3, pp. 401-415. 
Appendix 1 - The different implementation initiatives found in the sample's implementation plans listed according to the TQM main element to which they were assigned.

\begin{tabular}{ll}
\hline MANAGEMENT PROCESS & MARKET FOCUS \\
create quality council / steering group & benchmarking \\
quality assurance processes & customer satisfaction survey \\
mission/vision development & generic benchmarking \\
teamwork - work management & supplier partnerships \\
business values development & business environment (current and future) analysis \\
quality policy / CI principles development and approval & competitive benchmarking \\
strategic objectives/goals development & diagnostic (quality issues) survey - customers \\
appoint quality officer/director & initiate customer open days \\
business process objectives/goals development & customer partnerships \\
flatten organisation structure & diagnostic (quality issues) survey - suppliers \\
integrate business planning and quality goals/plans & focus on external customer satisfaction \\
establish quality objectives/goals & supplier audit / rationalisation \\
customised quality leadership process & supplier development \\
initiate flagship improvement projects & customer input
\end{tabular}

gain management commitment

implementation/action plan development

initiate quality improvement projects

restructuring

standards of performance

appoint business development/QA director or quality

manager

board agreement to develop TQM concept group-wide

disband/localise central quality resources (QC/SG chains)

identify TQM leadership / TQM champion(s)

planning process

strategic plan development

customised quality management process

focus on cost improvements

health, safety and environmental focus

ISO9000 plan development 
long-range improvement plan development

manage continuous improvement

introduce policy deployment

\section{PROCESS FOCUS}

control measures for the process

process improvement teams

internal customer/supplier concept

problem solving methods

QFD

reorganisation to process management

technology improvement

complaint management

corrective action system / error reduction programme

develop quality tools

\section{FMEA}

ownership of processes

process benchmarking

waste elimination
PEOPLE FOCUS

training - initiate organisation-wide cascade

TQM education course

teamwork - problem solving / improvement

training - quality tools and techniques

training - motivational

employee involvement

employee satisfaction survey(s)

recognition

revise remuneration system

suggestion schemes

learning forum

quality circles

rewards

empowerment

people development

change in status

diagnostic (quality issues) survey - managers / employees

identify and plan training needs

introduce incentive bonus / profit sharing scheme

teamwork - customer action

develop education/training strategy/plan

job description

\section{COMMUNICATION \& MEASUREMENT}

develop communication/feedback channels

formal self-assessment

solicitation/awareness event

business/quality metrics 
solicitation/awareness - general

TQM research - general

diagnostic (quality issues) survey - internal/cost of quality

employee performance evaluation/appraisal

solicitation/awareness (all management)

TQM research - business effectiveness

develop performance measurement system

quality award submission - AQA

introduce team briefing / regular communication/quality meetings

introduce periodic reviews

quality audit

link between measures and vision development

philosophy of the business

quality costing introduction

instigate quarterly reviews

"in process measurement and display" introduction 
Table 1 - Summary of literature review of change process phases

\begin{tabular}{|c|c|c|c|c|c|c|}
\hline $\begin{array}{l}\text { Edwards and } \\
\text { Hodgson [7] }\end{array}$ & $\begin{array}{l}\text { 1st phase } \\
\text { providing the vision }\end{array}$ & $\begin{array}{l}\text { 2nd phase } \\
\text { management action }\end{array}$ & $\begin{array}{l}\text { 3rd phase } \\
\text { increasing the } \\
\text { participation }\end{array}$ & $\begin{array}{l}\text { 4th phase } \\
\text { business alignment }\end{array}$ & 5th phase & 6th phase \\
\hline $\begin{array}{l}\text { Ghobadian et al } \\
\text { [16] }\end{array}$ & conformance quality & $\begin{array}{l}\text { customer driven } \\
\text { quality }\end{array}$ & market driven quality & strategic quality & & \\
\hline Foster et al [10] & start-up & honeymoon & transformation & $\begin{array}{l}\text { decline OR new } \\
\text { TQM model }\end{array}$ & & \\
\hline $\begin{array}{l}\text { Kanji and Asher } \\
\text { [30] }\end{array}$ & $\begin{array}{l}\text { identification and } \\
\text { preparation }\end{array}$ & $\begin{array}{l}\text { management } \\
\text { understanding and } \\
\text { commitment }\end{array}$ & $\begin{array}{l}\text { scheme for } \\
\text { improvement }\end{array}$ & $\begin{array}{l}\text { new initiative with } \\
\text { new targets and } \\
\text { critical examination }\end{array}$ & & \\
\hline Glover [19] & awareness & education & structural change & necessary activities & $\begin{array}{l}\text { expected } \\
\text { improvements }\end{array}$ & \\
\hline Beer et al [2] & $\begin{array}{l}\text { mobilize commitment } \\
\text { to change through } \\
\text { joint diagnosis of } \\
\text { business problems }\end{array}$ & $\begin{array}{l}\text { develop a shared } \\
\text { vision of how to } \\
\text { organize and manage } \\
\text { for competitiveness }\end{array}$ & $\begin{array}{l}\text { foster consensus for } \\
\text { the new vision, } \\
\text { competence to enact } \\
\text { it, and cohesion to } \\
\text { move it along }\end{array}$ & $\begin{array}{l}\text { spread revitalization } \\
\text { to all departments } \\
\text { without pushing it } \\
\text { from the top }\end{array}$ & $\begin{array}{l}\text { institutionalise } \\
\text { revitalization through } \\
\text { formal policies, } \\
\text { systems and } \\
\text { structures }\end{array}$ & $\begin{array}{l}\text { monitor and adjust } \\
\text { strategies in response } \\
\text { to problems in the } \\
\text { revitalization process }\end{array}$ \\
\hline Merli [36] & $\begin{array}{l}\text { initial situation } \\
\text { (conventional } \\
\text { approach) }\end{array}$ & $\begin{array}{l}\text { organization of/for } \\
\text { continuous } \\
\text { improvement }\end{array}$ & $\begin{array}{l}\text { management by } \\
\text { processes }\end{array}$ & $\begin{array}{l}\text { complete the } \\
\text { implementation of } \\
\text { TQM }\end{array}$ & & \\
\hline
\end{tabular}


Figure 1 - Process used for derivation of the questions

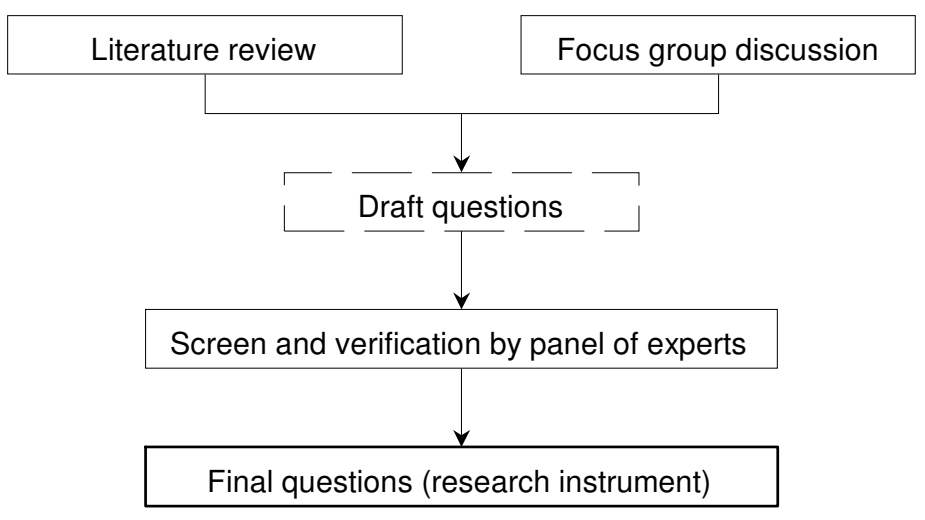

Figure 2 - The salient elements of TQM

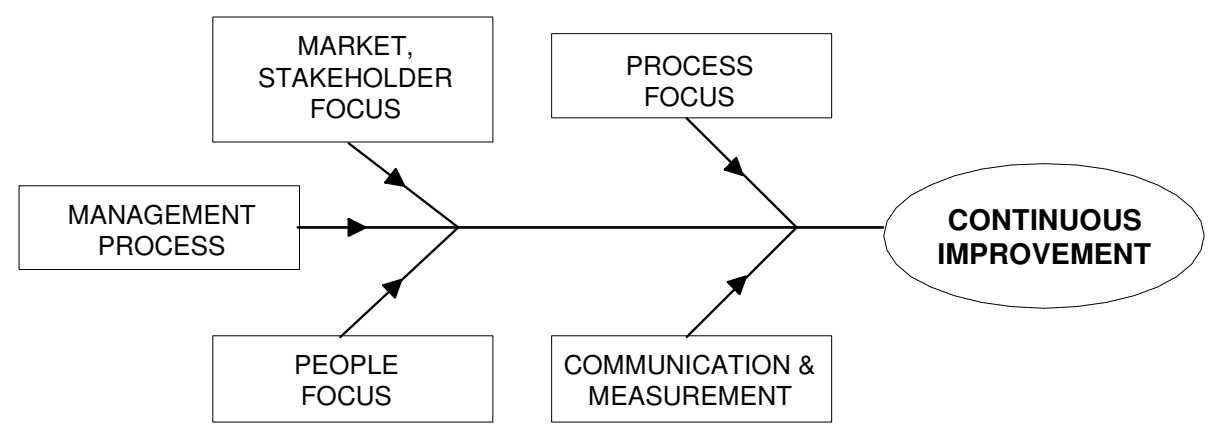

Figure 3 - Focus of the TQM implementation process activity

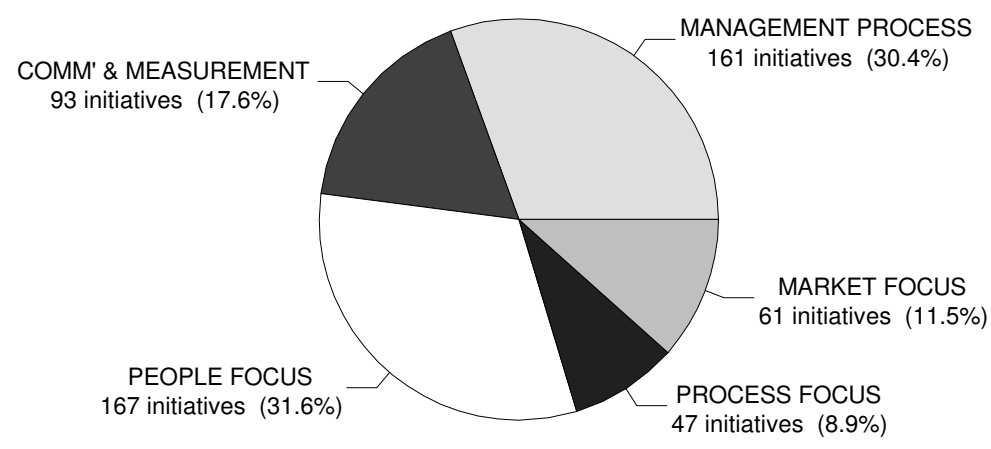


Figure 4 - Extent to which the implementation initiatives of the sample's implementation plans support seventeen proposed "desirable outcomes" during the process of TQM implementation.

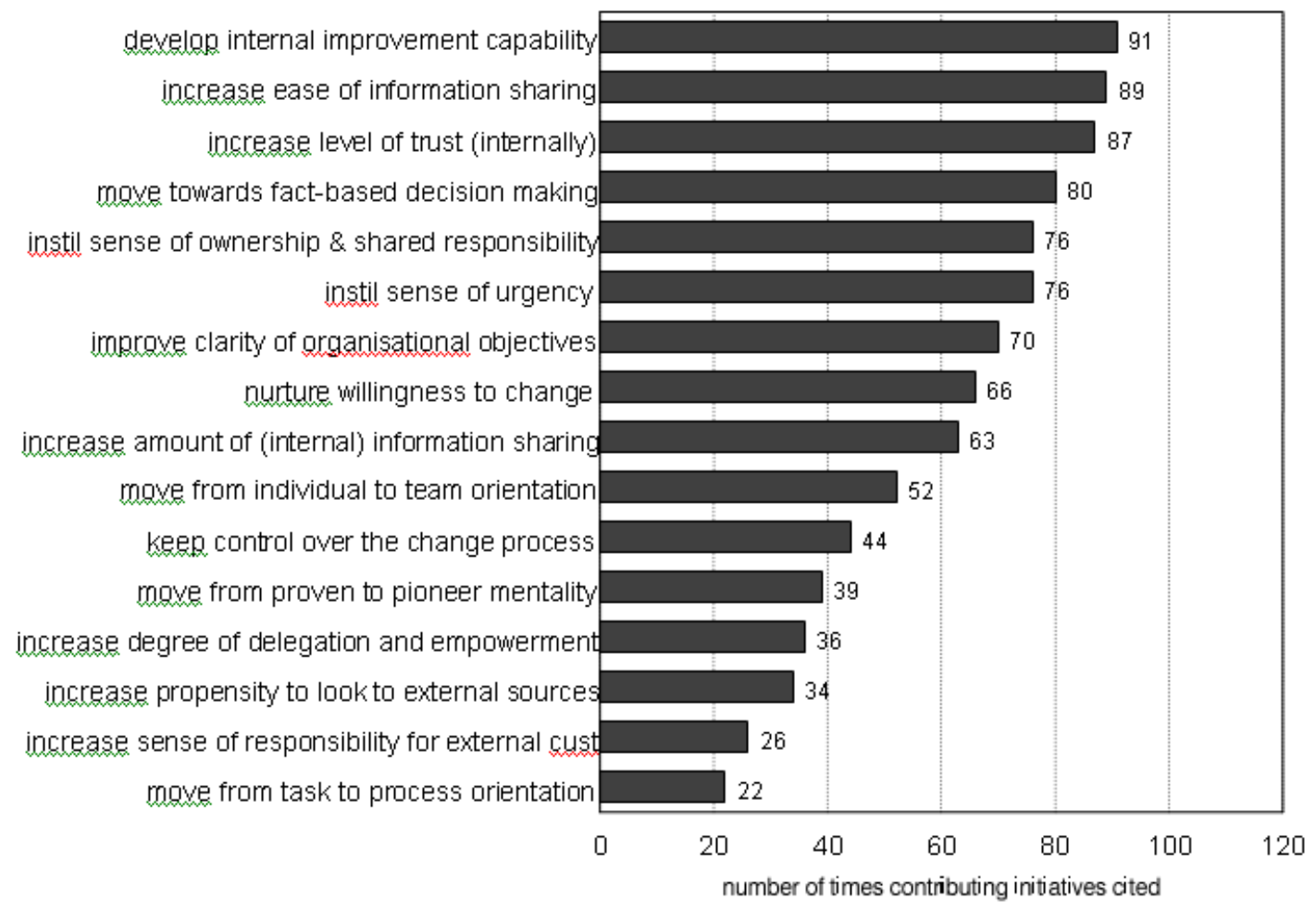

Figure 5 - Quantitative contribution of the five main elements to implementation phases 1 - 4

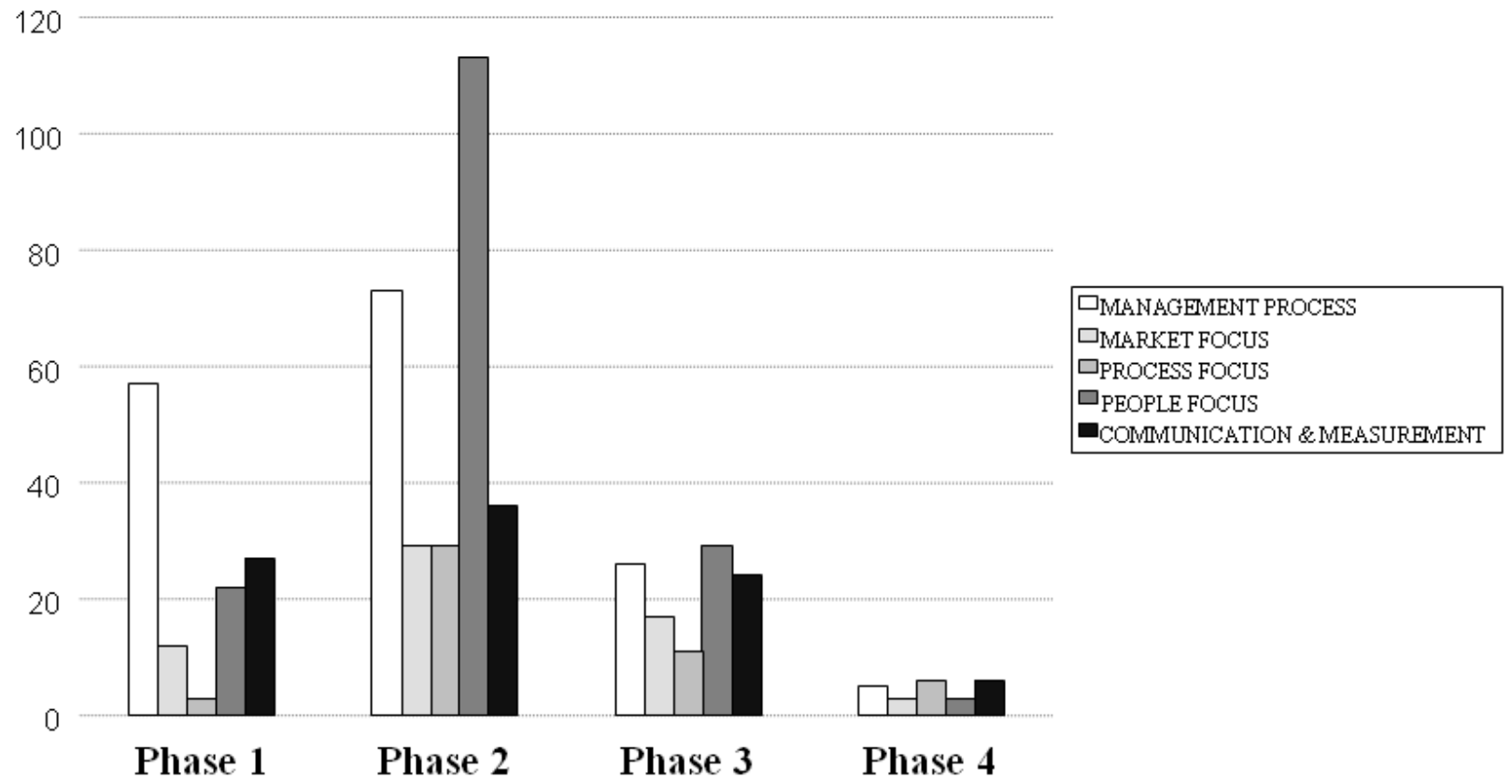


PRE

IMPLEMENTATION

"PLANNED"

IMPLEMENTATION

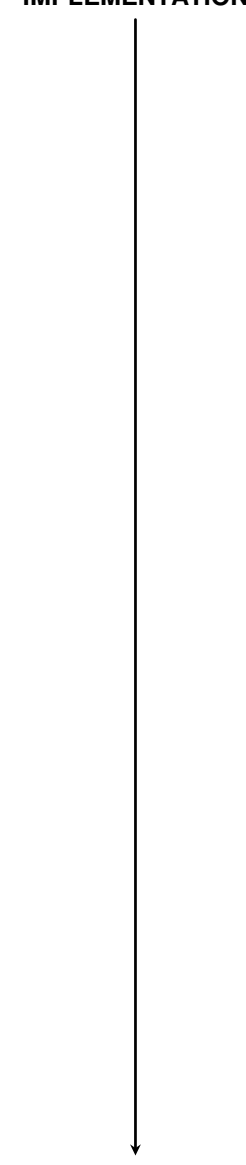

"EVOLUTIONARY" IMPLEMENTATION

(Re-focussing)
PREPARATION and AWARENESS

Key objectives:

- Develop detailed knowledge of TQM expectations and implications

- Establish TQM leadership and development team

- Establish priorities

- Identify ownership and responsibilities

Communicate the intention to introduce TQM to the organisation

Primary focus is on MANAGEMENT PROCESS

Concerned with initiatives that

- establish organisational direction and provide organisational

guidance by: improving clarity of organisational objectives and establishing mechanisms to keep control over the change process

- instil a sense of urgency for change

- develop a detailed knowledge of the actions required to develop internal improvement capability

Primary focus in on PEOPLE and COMMUNICATION (maintaining focus on MANAGEMENT PROCESS)

Concerned with activities that:

- instil a sense of ownership and shared responsibility

- increase the degree of delegation and empowerment

- move members of organisation from an individual to a team orientation

- increase the amount of information sharing

Primary focus is on COMMUNICATION and MEASUREMENT

Concerned with activities that:

- increase the amount and further increase the ease of information (Consolidation) _ sharing

- move the organisation from perceptive decision making to fact-based decision making

- ensure the clarity of organisational objectives

Primary focus is on PROCESSES and CUSTOMERS/MARKETS

Concerned with activities that:

- move the organisation from a task to a process orientation

- increase the sense of responsibility for the external customer

- increase the propensity to look to external sources

- move the organisation from a proven to a pioneer mentality 